\title{
CAMINHOS DA VISIBILIDADE: A ASCENSÃO DO CULTO A JUREMA NO CAMPO RELIGIOSO DE RECIFE
}

\author{
Michelle Gonçalves Rodrigues* \\ Roberta Bivar Carneiro Campos**
}

cognição é uma das mais básicas e evidentes capacidades do
homem, e é através dela, que o homem sempre procurou ajus-
tar o fenômeno de sua existência ao espaço que o circunda, respondendo aos eventos que neste venham a ocorrer, seja a tentativa de adaptar o mundo à sua cognição ou a de adaptar sua cognição ao mundo, criando assim a realidade. Esta se configura em um horizonte a ser seguido, dando sentido à existência ontológica e antropológica do homem. Em consequência do conhecimento nunca ser um fim em si mesmo, quando deparado com a realidade, esta se recusa veementemente à captação, é que se desenvolve a ideia de pluralismo cognoscitivo como forma de apreender e compreender as diversas realidades existentes, uma vez que estas se constituem como edificações socioculturais variando de uma cultura a outra.

Assim, o pluralismo cognoscitivo é a representação e a homologação do fato de que todos os homens, e/ou sociedades, somente podem alvejar um horizonte relativamente real e conhecer versões parciais desta

Doutoranda do Programa de Pós-Graduação em Antropologia da Universidade Federal de Pernambuco. michellezarodrigues@gmail.com

** Professora no Programa de Pós-Graduação em Antropologia da Universidade Federal de Pernambuco.robertabivar@gmail.com 
realidade, não podendo de forma alguma assumir o status de detentores de uma verdade única. Desta forma, o pluralismo cognoscitivo constitui um leque infinito de formas e possibilidades de pensamentos e reflexões. E, paradoxalmente, quanto mais reconhecemos a impossibilidade de apreensão do real em sua totalidade, mais nos aproximamos dele, uma vez que maior será a dimensão que dele teremos.

Neste artigo, a ideia do pluralismo cognoscitivo será o mediador entre religião e política. $\mathrm{O}$ processo de racionalização da modernidade trouxe o fim das antigas certezas e com ela a religião chegou ao fim de sua antiga função de estruturar a sociedade. A religião se transforma em religiosidade no mundo secularizado, ela se retira para o interior da pessoa, tornando-se uma crença pessoal. ${ }^{1}$ Entretanto, quando a religião é vista como religiosidade, temos o campo da experiência prática que unifica emoções e ações em um caminho que reencanta novamente o mundo com um sentido religioso, nos fazendo questionar sobre os lugares dados à religião, ao seu caráter público e/ou privado.

A jurema será objeto da nossa abordagem exemplar para percorremos o caminho proposto. Desejamos contribuir com os estudos acerca da confluência entre os processos religiosos e políticos na temática sobre a jurema, uma vez que a literatura específica se mostra escassa. Muitos trabalhos a abordam de maneira descritiva, outros a partir de aproximações com a umbanda, com o catolicismo e em alguns casos com o candomblé ou xangô. ${ }^{2}$ Mas seu viés político ainda é inexplorado

1 Georg Simmel, Religião - Ensaios vol. 1, São Paulo: Olho d'Água, 2010.

2 Citamos como exemplo alguns trabalhos: Mário de Andrade, Música de feitiçaria no Brasil, São Paulo: Martins Editora, 1983; Luiz Assunção, O reino dos mestres: a tradição da jurema na umbanda nordestina, Rio de Janeiro: Pallas, 2006; Roger Bastide, "Imagens do Nordeste místico em branco e preto", O Cruzeiro (1945); Maria do Carmo Brandão e Luís Felipe Rios, "O catimbójurema do Recife, in Reginaldo Prandi (org.), Encantaria brasileira: o livro dos mestres, caboclos e encantados (Rio de Janeiro: Pallas, 2001), pp. 160-81; Luís da Câmara Cascudo, Meleagro: depoimentos e pesquisa sobre a magia branca no Brasil, Rio de Janeiro: Agir, 1978; Álvaro Carlini, Cachimbo e maracá: o catimbó da missão (1983), São Paulo: CCSP, 1993; Maria Rosário Carvalho, Edwin Reesink e Julie Cavignac (orgs.), Negros no mundo dos índios: imagens, reflexos, alteridades, Natal: EDUFRN, 2011; Clarisse Novaes Motta e Ulisses Pessoa Albuquerque (orgs.), As muitas faces da jurema: da espécie botânica à divindade afro-indígena, Recife: NUPEEA, 2006; Roberto Motta, "A jurema do Recife: religião indo-afro-brasileira em contexto urbano", in B. C. Labate e S. L. Goulart (orgs.), O uso ritual das plantas de poder (Campinas: Mercado de Letras, 2005), pp. 279-99; Sandro Guimarães de Salles, À sombra da jurema encantada: 
e é sobre esse prisma que pensaremos os atuais caminhos da visibilidade da jurema no campo religioso e seu lugar na constituição de uma arena política fundamentada pela religião.

\section{A jurema sagrada}

A jurema é uma religião tipicamente encontrada no nordeste brasileiro. Sua presença estende-se entre áreas do sertão e urbanas. É recente o interesse acadêmico sobre o tema, no que diz respeito ao encontro da jurema no espaço urbano, que envolve a confluência de vários outros tipos religiosos, como a umbanda, o catolicismo, o candomblé e o vodum maranhense. Seu nome, de origem tupi, liga-se a espécies de árvores encontradas no sertão. São elas a Mimosa hostilis, hoje reclassificada como Mimosa tenuiflora, a Mimosa verrucosa e também a Vitex agnus-castus, conhecidas como jurema preta, jurema mansa e jurema branca, respectivamente. ${ }^{3}$ A jurema preta é utilizada na fabricação da bebida que dá nome a esse universo religioso. Sua origem remonta a pajelança e ao toré, ambos regimes religiosos que fundamentam a estrutura indígena do sagrado.

No caso específico de Pernambuco, a jurema era inicialmente tida como um culto um pouco escondido dentro dos terreiros de religião de matriz africana, um culto secundário aos orixás. ${ }^{4}$ Entretanto, o "quarto

mestres juremeiros na umbanda de Alhandra, Recife: UFPE, 2010; Waldemar Valente, Sincretismo religioso afro-brasileiro, São Paulo: Nacional, 1955; René Vandezande, "Catimbó: pesquisa exploratória sobre uma forma nordestina de religião mediúnica" (Dissertação de Mestrado, Universidade Federal de Pernambuco, 1975).

3 Clarice Novaes da Mota e José Flávio Pessoa de Barros, "O complexo da Jurema: representações e drama social negro-indígena", in Clarice Novaes da Mota, Ulysses Paulino de Albuquerque (orgs.), As muitas faces da Jurema: de espécie botânica a divindade afro-indígena (Recife: Bagaço, 2002), pp. 19-60.

4 Neste ponto, desejamos destacar que muito provavelmente os motivos dessa invisibilidade residem na dicotomia magia/religião como juízos valorativos. A perseguição sofrida pelos terreiros, principalmente durante os anos do Estado Novo, os coloca sob a tutela da polícia acompanhados do jargão charlatanismo. Em 1933, é criado em Pernambuco o Serviço de Higiene Mental, liderado por Ulisses Pernambucano e tendo entre seus intelectuais Gilberto Freyre, Gonçalves Fernandes, René Ribeiro, entre outros. De forma bem simplificada, o SHM foi uma tentativa de elevar o candomblé à categoria de religião, colocando-o como um componente na formação do Brasil e retirando-o da alçada policial. O mesmo não aconteceu com a jurema, que continuou a ser reconhecida como magia e, principalmente, acusada de charlatanismo e falsa medicina por realizar trabalhos de cura. Essa postura frente à jurema fez com que seus altares fossem escondidos nos terreiros. 
da jurema", onde se encontram os assentamentos e seu peji ou altar, está hoje, em muitos casos, dentro do salão do candomblé, ao lado do "quarto do santo", um espaço destinado aos assentamentos dos orixás. Candomblé e jurema dividem o mesmo espaço temporal e espacial dentro de muitos terreiros, ${ }^{5}$ embora seus cultos sejam separados. Dessa forma, a jurema foi ressignificada dentro do cenário afro-religioso pernambucano, e o próprio candomblé sofreu sua influência. A jurema apropriou-se da cosmologia africana aliando-a a cosmologia indígena. A jurema também foi ao encontro da umbanda, do espiritismo kardecista e do catolicismo popular ao incorporar o universo cristão na figura dos santos católicos e de Jesus Cristo.

Como já foi dito, os vários elementos religiosos presentes nas sessões de jurema, também chamadas de sessões de catimbó, agregam várias cosmologias religiosas: o maracá, um chocalho que marca todas as sessões; as toadas que versam sobre a história da jurema e seus significados, assim como as histórias de suas entidades. Além da estrela do Rei Salomão, outros objetos litúrgicos compõem a mesa da jurema, seu altar ou peji: a princesa, um recipiente com água ou o vinho da jurema, nome dado à bebida feita através da raiz ou da casca maceradas da jurema preta. Também podemos encontrar o príncipe, copo ou taça com água ou a bebida jurema; velas; imagens de caboclos, mestre e santos; crucifixos; cachimbo e fumo; as oferendas e os assentamentos. Em todos os altares temos a presença do tronco da jurema, um pedaço do tronco da própria árvore que após passar por uma ritualística encarnaria a entidade do mestre do juremeiro.

O panteão da jurema é ordenado pelos caboclos, divididos em índios, personagens do sertão nordestino ou sertanejos, o boiadeiro e ainda aqueles que simplesmente viveram nas matas, pelos mestres e mestras e pelos exus, também chamados de trunqueiros. Os últimos demonstram a influência do universo afro-indígena dentro da jurema. Quanto aos mestres, esses são pessoas que viveram e que depois de sua

\footnotetext{
Ressalvamos que a presença da jurema nos terreiros de candomblé não pode ser entendida como uma ocorrência geral. Há casas que somente se destinam ao candomblé e casas que cultuam somente jurema. Estas últimas, geralmente, não são terreiros, mas o local de moradia do juremeiro, que tem ali seu altar de jurema e onde realiza suas consultas.
} 
morte se apresentam como entidades que auxiliam os juremeiros e todos que procuram a ajuda da jurema por alguma razão. ${ }^{6} \mathrm{Em}$ muitos casos esses mestres foram figuras da História do Brasil, como o mestre Corisco, que em vida compôs o grupo de Lampião, e Malunguinho, hoje visto como uma das principais entidades da jurema, líder do Quilombo do Catucá - PE. ${ }^{7}$ Temos ainda os ciganos e os preto-velhos, numa clara reapropriação a partir da umbanda.

Quando comparamos a jurema ao candomblé, em termos ritualísticos, as diferenças são nítidas. ${ }^{8}$ De um lado, temos as toadas cantadas em português e de outro, em iorubá; as vestimentas também diferem, na jurema há um espetáculo de cores nos tecidos de "chita" usados pelas juremeiras, enquanto no candomblé cada filha e filho de santo veste a cor específica de seu orixá, quando não estão todos de branco. A jurema pode ser celebrada em ritos festivos que são embalados ao ritmo do coco, em que, na maioria das ocasiões, são os próprios mestres/entidades os cantantes, e também em rituais chamados de "jurema de mesa". Esses últimos caracterizam-se pela presença de um número menor de pessoas, fechado ao público, as vestimentas já não são coloridas, mas brancas, e a alegria característica da festa, com toques de ilús e danças, ${ }^{9}$ dá lugar a uma tímida entoação das cantigas acompanhadas de rezas e do barulho do maracá ao redor de uma mesa ou de uma toalha colocada ao chão. A presença marcante da fumaça está nos dois tipos de rituais. Os juremeiros invertem seus cachimbos colocando o fornilho (onde se queima o fumo) na boca o soprando a fumaça que sai através da piteira. A fumaça é responsável pela limpeza, ela eleva os desejos dos fiéis ao mesmo tempo em que comunica o desejo das entidades.

Nessa pequena descrição o que mais nos chama atenção nas es-

6 São diversos os motivos que levam as pessoas à jurema, entre os mais corriqueiros podemos citar problemas de saúde, financeiros e amorosos.

7 Malungo era o título dado à liderança do Quilombo do Catucá - PE (1817-1830) e significa amigo, companheiro de viagem.

8 Apesar de falarmos sobre o candomblé, nos deteremos mais especificamente nas descrições da jurema por ser esta o ponto central de nosso argumento, além de compreendermos as inúmeras etnografias já realizadas sobre o candomblé e que podem ser tomadas como modelos descritivos do ritual para o presente trabalho.

9 Nome dado aos tambores tocados na jurema e no candomblé. 
truturas dos cultos é a diferença entre as entidades da jurema (falantes/ cantantes) e do candomblé (os orixás não cantam, mas os fiéis) e a presença do cachimbo e sua fumaça durante todos os rituais, o que não ocorre no candomblé. Seguindo a definição proposta por Motta, inspirado em Victor Turner, a jurema seria um culto fortemente logofílico, amparado na língua e na metáfora, ao passo que o candomblé seria da ordem do iconofílico e do somatofílico. ${ }^{10}$

\section{Kipupa e Caminhada dos Terreiros de Pernambuco - da tradição ao espaço público}

Sabemos que a prática da observação participante nos permite uma maior aproximação com a comunidade pesquisada. É através dela que percebemos a importância de algumas ações e de alguns eventos. Ao nos referimos ao Kipupa e à Caminhada dos Terreiros, os tomamos como eventos que têm seus prolongamentos entre o passado e o presente, sendo possível estruturá-los na medida em que os dotamos de ordem e sentido. Sahlins nos diz que os eventos são acontecimentos de significância com um dado sistema simbólico, e que a ele é dado uma interpretação de acordo com os projetos pessoais de cada participante. ${ }^{11}$

Um evento é de fato um acontecimento de significância e, enquanto significância, é dependente na estrutura por existência e por seu efeito. "Eventos não estão apenas ali e acontecem", como diz Max Weber, "mas têm um significado e acontecem por causa desse significado." Ou, em outras palavras, um evento não é somente um acontecimento no mundo; é a relação entre um acontecimento e um dado sistema simbólico. $\mathrm{O}$ evento é a interpretação do acontecimento, e interpretações variam. ${ }^{12}$

Dessa forma, os eventos aqui trabalhados serão fontes de conhecimento para o processo de visibilidade da jurema, eventos estruturados numa lógica culturalista, como colocou Sahlins. Para o autor, os sistemas simbólicos são estruturadores da ação social, o que podería-

${ }^{10}$ Roberto Motta, "O corpo e a religião no xangô e na umbanda", Revista de Teologia e Ciências da Religião, ano VII, n. 7 (2008), pp. 55-69.

11 Marshal Sahlins, Ilhas de História, Rio de Janeiro: Jorge Zahar, 1990.

12 Sahlins, Ilhas de História, p. 191. 
mos entender como uma espécie de estruturalismo da práxis onde a compreensão das práticas sociais possibilita a compreensão dos diferentes significados culturais, ${ }^{13}$ entendendo o significado simbólico como variação de cada experiência social. Estamos diante da estrutura de conjuntura de Sahlins, a mediação entre estrutura e o evento através do significado cultural dos sistemas simbólicos. ${ }^{14}$

Ao falarmos em sistema simbólico nos remetemos a Geertz e caminhamos com o autor para o que ele chama de "reconfiguração religiosa da política do poder". ${ }^{15}$ Retomamos a ideia do conceito do beliscão do destino, desenvolvido por William James, um conceito subjetivo que exprime a experiência pessoal sobre a religião. ${ }^{16}$ Sentimentos, emoções, crenças vividas no interior dos sujeitos. Mas, como mesmo Geertz observou, como explicar as manifestações públicas do que entendemos como religioso?

Os eventos dos cem anos decorridos desde que James fez suas palestras - duas guerras mundiais, o genocídio, a descolonização, a disseminação do populismo e a integração tecnológica do mundo - menos contribuíram para impelir a fé para dentro, para as comoções da alma, do que para impulsioná-la para fora, para as comoções da sociedade, do Estado e desse tema complexo a que chamamos cultura. ${ }^{17}$

O autor nos dá exemplos de vários eventos ocorridos em muitas partes do mundo para trazer novamente a religião para o espaço público, para as questões públicas. Em momento anterior, Geertz nos diz que "os conceitos religiosos espalham-se para além de seus contextos especificamente metafísicos, no sentido de fornecer um arcabouço de ideias gerais em termos das quais pode ser dada uma forma significativa a uma parte da experiência - intelectual, emocional, moral". ${ }^{18}$ A religião é privada porque é uma experiência sentida e é pública porque é uma

13 Michelle Gonçalves Rodrigues, "Conhecimento e alteridade: história, estrutura, função, cultura e significado em três perspectivas antropológicas", CSOline - Revista Eletrônica de Ciências Sociais, ano 2, v. 5 (2008), pp. 242-65.

14 Sahlins, Ilhas de História.

15 Clifford Geertz, Nova luz sobre a Antropologia, Rio de Janeiro: Jorge Zahar, 2001, p. 157.

16 Geertz, Nova luz sobre a Antropologia.

17 Geertz, Nova luz sobre a Antropologia, pp. 151-2.

18 Clifford Geertz, A interpretação das culturas, São Paulo: LCT, 1989, p. 90. 
das esferas que constituem a realidade social dos sujeitos. Campos e Gusmão nos chamam atenção, através da imagem midiática religiosa, ou não, da peregrinação, para essa complementaridade entre a experiência subjetiva do beliscão do destino e a publicidade do sentido religioso, da identidade e do poder. ${ }^{19}$ Partimos, portando, da peregrinação a outros eventos religiosos.

O Kipupa Malunguinho é um evento idealizado por Alexandre L'Omi L'Odò, realizado pelo Quilombo Cultural Malunguinho (QCM) e que marca o encerramento da Semana Estadual de Vivência e Prática da Cultura Afro Pernambucana, instituída pela Lei Malunguinho 13.298/ 07, um projeto de lei formulado e aprovado pelo então deputado estadual Isaltino Nascimento. ${ }^{20}$ Embora o evento marque o fim da Semana, ele começou a ocorrer no ano de 2006, um ano antes da aprovação da Lei. De acordo com Alexandre L'Omi L'Odò, ${ }^{21}$ o termo quimbundo kipupa significa agregação de pessoas. Logo o Kipupa Malunguinho significa agregação de pessoas em volta da figura de Malunguinho. O evento ocorre em terras do antigo Quilombo do Catucá, zona da mata de Pernambuco, especificamente onde hoje é a cidade de Abreu e Lima.

[...] as pessoas iam vivenciar Malunguinho no espaço histórico onde foi Catucá mesmo, aquele espaço ali teve uma coisa muito importante. No ritual profundo de jurema dentro de uma mata fechada, que é uma coisa totalmente inusitada, difícil de acontecer, e possibilitando as pessoas de chegar. Entendeu? E o coco, que é uma coisa importante na jurema. O coco é essencial na jurema, também. [...] Porque é o ritmo que os mestres dançam, é o ritmo que é dos mestres. Porque o coco sempre foi do Nordeste e os mestres são figuras do Nordeste. Então, naturalmente, eles gostam de coco, que eles chamam de pisada, a macuca ou a ma-

19 Roberta Bivar Carneiro Campos e Eduardo Henrique Araújo de Gusmão, "Religião em movimento: relações entre religião e modernidade", Campos, v. 11, n. 1 (2011), pp. 65-83.

20 O QCM é uma entidade surgida, em 2004, a partir de um grupo de estudos realizado no Arquivo Público Estadual João Emereciano na cidade de Recife - PE, durante o período de 2004 a 2007. Os três principais líderes do QCM são Sandro de Jucá (pai de santo, juremeiro e coordenador religioso do QCM), Alexandre L'Omi L'Odò (filho de santo, juremeiro e coordenador do QCM) e João Monteiro (filho de santo, juremeiro e coordenador do QCM). Para maiores esclarecimentos http://www.qcmalunguinho.blogspot.com.br/.

21 Alexandre L'Omi L'Odò possui um blog constantemente atualizado sobre as ações realizadas pelo QCM e sobre assuntos que envolvem a jurema: 〈http://alexandrelomilodo.blogspot.com.br/> 
cumba deles. Aquele toque assim, tac rutac tac... É uma levada baseada na linha de coco e as toadas da jurema são linhas de coco. ${ }^{22}$

O ritual propriamente dito ocorre em uma mata na área rural do município de Abreu e Lima, mas a festa que congrega os juremeiros ocorre no pátio da casa de Juarez, um colaborador do QCM, a uma distância aproximada de 100 metros da mata. Em um determinado momento da festa as pessoas caminham até a mata, regressando para a festa após o fim do ritual.

Foi no dia 25 de setembro de 2011, um domingo, o VI Kipupa Malunguinho. Pessoas vestidas de branco, algumas vestidas de chita, outras com estampas variadas. Eram muitos participantes. As mesas já estavam repletas. Muitos juremeiros traziam em seus braços garrafas de bebida, frutas soltas para serem ofertadas, cestos já recheados de frutas e nas mãos estavam seus cachimbos. Um grande grupo muito animado chegou, pareciam ser todos de uma mesma família de terreiro, vestiam branco e se colocaram em frente ao altar preparado para Malunguinho. Dois homens carregavam um grande cesto com frutas que foi colocado sobre as folhas de bananeira distribuídas ao chão. Logo atrás, mais um homem com um balaio nos ombros. Em seus pescoços grandes guias feitas com a semente ave-maria. Dois ogãs traziam nos ombros dois ilús. Colocaram ao lado do altar e começaram a tocá-los. As oferendas já colocadas sobre o altar, os juremeiros pegaram seus cachimbos ao som alto dos batuques. Cantos e palmas acabam por constituir a orquestra para Malunguinho. Cuias com farofa e mingau foram depositadas no altar. A fumaça começou a se espalhar na defumação das oferendas. Um cheiro das ervas do fumo se espalhou e com ele a turvidez da jurema começou seu trabalho. Em meio à fumaça os juremeiros mandaram seus recados, receberam das entidades suas respostas, pediam proteção, guerreavam, falavam a Malunguinho que estão em suas terras, o Quilombo do Catucá. A jurema fala através da fumaça, os juremeiros a sabem ler. A fumaça faz a intermediação entre os mundos, ela corre as cidades da jurema, lugar de moradas das entidades. E a grande

${ }^{22}$ Depoimento de Alexandre L'Omi L'Odò em 14 de maio de 2011. 
neblina em que se transforma o ar é o esconderijo e a emanação de suas forças, a ciência da jurema.

Os cantos continuaram, o altar já estava repleto de oferendas. Muitas frutas dispersas sobre o chão, em balaios e gamelas, garrafas de cachaça, vinho e velas. A orquestra para Malunguinho seguiu a tocar suas toadas. Pelo pátio mais e mais pessoas. Uma confraternização para saudar Malunguinho da jurema sagrada. Os juremeiros ao encontrarem-se, abraçavam-se, uma alegria embalava seus rostos, contagiava seus corpos ao som do coco. Como em extensão ao terreiro, a comida se torna um momento de união. Muitos traziam em suas bolsas o almoço de domingo. Ao redor das mesas famílias almoçaram juntas. Muitos, ainda, compraram os alimentos preparados pela família de Juarez. Foi uma tarde de muito calor, o sol pernambucano estampava o suor no rosto de todos.

Na tenda armada no pátio, a poucos passos do altar destinado as oferendas para Malunguinho, Alexandre L'Omi L'Odò, ao microfone, pedia a atenção dos presentes e chamava algumas pessoas ligadas ao QCM. Ele disse algumas palavras, falou sobre o significado do Kipupa, sobre o Quilombo do Catucá, sobre a jurema, a discriminação sofrida até mesmo entre os juremeiros que não a assumem perante a sociedade mais abrangente, deu algumas informações sobre o que aconteceria e em seguida passa o microfone para João Monteiro. João é historiador e por esse fato sua fala se direciona a legitimar Malunguinho como uma figura histórica e a incitar estudos dentro dos terreiros para uma melhor formação dos fiéis, principalmente para dialogar com o Estado:

[...] Porque senão gente, a gente vai passar, a gente vai continuar passando despercebido do Estado, quando não, a forma que o Estado tenta nos reconhecer é uma forma que não tá legal. Não tá legal a forma que o Estado tá se propondo a reparar os danos causados nos últimos 400 anos não está legal. Não existe política pública para o povo de terreiro. Não existe política pública. E, nós estamos muitas vezes sendo tratados como massa de manobra e o Quilombo Cultural Malunguinho está de olho pra denunciar todos os momentos que fomos feitos de massa de manobra, doa a quem doer. Certo? Nós estamos aqui pra isso, pra denunciar. O Estado se quiser reparar, então, vai reparar com dignidade, 
reparar com folclore não dá. A nossa fase de ser visto como folclore passou. Hoje, somos povo de terreiro. Certo? E temos o nosso espaço [...]. ${ }^{23}$

Alexandre, que faz graduação em história, retomou o microfone e citou diversos nomes de religiosos ali presentes, falou sobre juremeiros que vieram de outros estados e outras regiões do país. Citou também nomes de professoras da rede estadual de ensino que estavam participando do Kipupa, inclusive tendo levado alguns alunos. Entre elas, estava a professora Carmem Dolores:

[...] Nenhuma mudança, em nada, vai acontecer no mundo, na educação no Brasil, se não for pela educação, a educação é o grande transformador da sociedade. Tem que quebrar barreiras, porque às vezes a criança em casa é educada, ela vive no meio do candomblé, ela vive no meio da religião e na escola ela se sente humilhada, ela se sente ofendida. Porque na escola, infelizmente, a gente vê que o racismo institucional na própria escola provoca. Por que o que a gente vê que a criança estuda na escola? A criança estuda a Bela Adormecida que é loira dos olhos azuis, a criança estuda Chapeuzinho Vermelho, a criança só estuda o padrão europeu. É isso que as crianças estudam. E nós precisamos lutar pra que isso, realmente, seja [...] a tolerância na escola aconteça. Isso só vai acontecer, com certeza, se todos nós que estamos aqui podemos lutar e reivindicar do Estado, da escola, que é importante o respeito e a diversidade no na sociedade brasileira. ${ }^{24}$

Após a fala de várias outras pessoas ligadas à jurema de alguma maneira e a entoação de alguns cantos seguimos em direção à mata para o ritual propriamente religioso. Os juremeiros levaram as oferendas depositadas no altar para a mata de Malunguinho. Ao fim do ritual a festa no pátio da casa de Juarez foi retomada no constante ritmo do coco, em que vários grupos musicais dividem o palco.

O Kipupa é a ação de visibilidade da jurema mais expoente do QCM. Com uma ocorrência anual, por isso é considerada dessa forma, todo o grupo se organiza em torno do evento. Convites são enviados, contatos são feitos, alianças e parcerias com outras entidades são bus-

23 Fala de João Monteiro na cerimônia do dia 25 de setembro de 2011.

${ }^{24}$ Fala da professora Carmem Dolores na cerimônia do dia 25 de setembro de 2011. 
cadas. Fotógrafos profissionais, documentaristas pessoas ligadas à TV também participam e dão como contribuição o material produzido durante o evento. Ainda segundo Alexandre L'Omi L'Odò:

Assim, o objetivo do evento é manter viva a memória e história, além do imaginário que cerca toda essa cultura, construindo o sentimento de pertencimento e reconhecimento nacional a estes líderes negros e indígenas, através das discussões de temáticas socioeducacionais, culturais e religiosas, com a participação de toda comunidade, em especial os mestres e mestras da cultura tradicional e popular, pesquisadores (da academia ou não) e interessados, materializando em matas fechadas do antigo quilombo de Malunguinho uma possibilidade de imersão na experiência do corpo e espírito, através de debate, ritual (liturgia da jurema) e o grande coco sagrado da mata.$^{25}$

Nesse ponto, já podemos delinear que os caminhos que levam à visibilidade da jurema vão além do ritual religioso, abarcando o contexto histórico para legitimar a figura de Malunguinho e, em consequência, a jurema, a instituição escola, a presença de juremeiros de outras cidades de Pernambuco e outros estados do Brasil, tendo inclusive a presença de representantes da Escola de Umbanda Caboclo Sete Flechas de São Paulo participando e filmando todo o evento. Essa filmagem se tornou um DVD sobre a jurema, vendido pelos representantes da Escola de Umbanda. Outro trabalho do tipo é desenvolvido pelo fotógrafo e documentarista Felipe Peres, em uma série exibida na TV Universitária da UFPE sobre Malunguinho.

Já a Caminhada dos Terreiros de Pernambuco tem um alcance maior. Além de abarcar a jurema, também congrega o candomblé e a umbanda, num cortejo pelas ruas centrais do Recife. A Caminhada acontece em meio ao centro da cidade, sob a vista dos mais diversos segmentos sociais e com a cobertura da mídia recifense. No ano de 2011, foi sua quinta edição, abrindo o mês da Consciência Negra, no dia 4 de novembro.

${ }^{25}$ Disponível em <http://alexandrelomilodo.blogspot.com.br/2011/09/o-que-significa-kipupamalunguinho.html>. É interessante notar que os caminhos da visibilidade da jurema, neste trabalho, vão além dos eventos em que nos propomos a abordar. Eles perpassam os blogs de divulgação do QCM, porém essa observação já seria por si só motivo de outro trabalho. 
A Caminhada surgiu a partir da discussão do projeto Memorial Águas de Iemanjá, no ano de 1997. Esse projeto diz respeito a um memorial, hoje já construído na Praia do Pina em Recife, de referência religiosa para o candomblé pernambucano. Porém, apesar de o projeto ter surgido no ano de 1997, somente em 2007 o memorial foi construído e a Caminhada tomou corpo. Em conversas informais e também em algumas entrevistas que realizamos sobre a Caminhada de Terreiros, o nome de Marcos do Grac foi citado como o primeiro idealizador do evento, para ele:

[...] essa Caminhada surgiu e teve como propósito, na verdade, reivindicar e mostrar o papel do candomblé em Pernambuco, que não é pouco, Pernambuco tem uma referência, inclusive muito grande, porque aqui se chegou em 1532, a primeira nação, que foi o povo banto que chegou. E esse trabalho desse povo veio até hoje, que é o trabalho de procurar respeito, visibilidade na luta, na época inclusive nessa questão do racismo, e a luta que, inclusive, Zumbi encampou, era a luta pela liberdade. Então, a partir daí, essa Caminhada se tornou a grande referência não só para a cidade e para o estado, mas para o Brasil e fora do Brasil. Nós estivemos inclusive representando no encontro de preparação do Fórum Social Mundial essa discussão. Então, tanto a Caminhada como o Memorial de Iemanjá são pontos fundamentais das religiões de matriz africana e para os terreiros de candomblé como um todo. Porque dentro disso tem a questão, em Pernambuco a umbanda tá fazendo 101 anos. E a questão da jurema é fundamental porque foi a consolidação do candomblé, de matriz africana, com a questão dos índios, porque os índios tiveram papel importantíssimo nessa questão da coligação, porque foram eles que adaptaram os negros as suas florestas e aqui desenvolveram as suas raízes junto [...].

Ainda segundo Marcos:

[...] Essa nossa ida, agora, pra uma reunião com a Ministra da Igualdade Racial é um reflexo disso que tá acontecendo no Brasil, e Pernambuco é a grande influência. Segundo o Ministério tem-se dito o seguinte, que Pernambuco tem um diferencial do Rio de Janeiro que é um conjunto de religiões que vão às ruas e tal, de Salvador que agrega samba, reggae, todos os grupos de tambores, diferentemente de São Luís do Maranhão que leva bumba-meu-boi pra rua. Pernambuco é um cortejo religioso 
que canta o xirê de Exu a Oxalá e faz um complemento com a jurema e com a umbanda. Então isso, coloca pra esse estado e pra gente um orgulho muito profundo e uma responsabilidade muito grande de que a gente, a partir dessa visão, a gente não pode errar. Ou a gente continua dentro da mesma linha, buscando a educação, dando visibilidade, capacitando, criando espaço pra que o povo de terreiro ocupe, conheça profundamente, inclusive, a religião. Enfim, é um trabalho e uma posição política forte porque a gente começa a reivindicar os espaços, ou seja, políticas públicas para o povo negro. ${ }^{26}$

No início a Caminhada foi um pouco tímida, o cortejo não era nas ruas centrais de Recife, mas nos arredores do Memorial Águas de Iemanjá. E o nome da Caminhada era outro, Primeira Caminhada contra Descriminação Religiosa e Racial. Nos anos posteriores, a Caminhada foi levada para o centro de Recife, num cortejo em que "o povo de santo toma as ruas de Recife!", nos dizeres de Claudilene, membro da Secretaria de Educação da Prefeitura de Recife, no primeiro ano da Caminhada. Campos adverte que embora a ideia de identidade cultural suponha uma equivalência entre uma identidade e uma cultura, no mundo globalizado isto não parece tão evidente porque se supõe um compartilhamento cultural. ${ }^{27}$ Entretanto, as identidades são reivindicadas com base em diferenças culturais e isso possibilita novos rearranjos nas formas políticas.

Era sexta-feira, 4 de novembro de 2011, quando a comunidade de terreiro pernambucana se concentrava na área conhecida como Marco Zero. Uma multidão se espremia tomando também as ruas adjacentes. A maioria das pessoas se vestia de branco. No centro do Marco Zero havia um pequeno palco. Um pouco à frente, na rua, um grande trio elétrico. No palco várias lideranças religiosas se pronunciaram, mas a presença não se estendeu apenas aos religiosos, o próprio prefeito de Recife, João da Costa, se pronuncia em favor da liberdade religiosa e enalteceu as raízes ancestrais africanas na formação da referida cidade e também do estado de Pernambuco, embora não tenha acompanhado o cortejo.

A concentração para a Caminhada fora marcada para as 15 horas.

26 Depoimento de Marcos do Grac no dia 13 de3 dezembro de 2011.

27 Roberta Bivar Carneiro Campos, "Les Défis de Xambá: un terreiro Devenu Quilombo: analyse du syncretisme et de l'africanité", Cahiers du Brésil Contemporain, n. 75/76 (2010), pp. 91-112. 
Um pouco antes, juremeiros começaram a se reunir na conhecida Rua da Guia, nos arredores do Marco Zero. Essa rua tem uma forte conotação para os juremeiros, era ali que muitos mestres e mestras da jurema, em vida carnal, frequentavam os estabelecimentos de meretrício. $\mathrm{O}$ motivo para se reunirem derivou de um desentendimento entre a coordenação da Caminhada e os coordenadores do QCM. Entretanto, todo conflito gera outra "possibilidade", um novo rearranjo na vida social. Desse conflito foi lançada, por Alexandre L'Omi L'Odò, a Rede Nacional do Povo da Jurema, hoje com duzentos juremeiros ligados a ela.

Mas voltemos à Caminhada. Durante o percurso, que vai do Marco Zero ao Pátio da Igreja do Carmo (onde foi morto Zumbi dos Palmares e exposto seu corpo, portanto um lugar muito significativo para toda a comunidade de terreiro), são entoados somente cantos do candomblé. Todos os orixás são louvados. Os religiosos que cantam as toadas se posicionam no trio elétrico. Ali também outros personagens ligados ao poder público fazem suas manifestações. É o caso de Rosilene Rodrigues, Diretoria da Igualdade Racial da Secretaria Municipal de Direitos Humanos e Segurança Cidadã da Prefeitura de Recife, que embora faça parte do candomblé, estava ali, naquele momento, representando a prefeitura. Vejamos a sua apresentação:

Aqui nasceu e foi pro mundo o Quilombo dos Palmares. Essa cidade é uma cidade de resistência, foi aqui que Zumbi provou a primeira sociedade baseada no respeito aos diferentes. Então, Recife não poderia deixar jamais de provar e mostrar a cada tijolo, a cada prego, a cada ponte, que nós estamos vivos. Não é por nada que somos mais de $70 \%$ da população. Homens e mulheres negras que resistem em todos os cantos dessa cidade. E é com esse compromisso que a Prefeitura da Cidade do Recife vem implementando políticas que deem conta dessa realidade [...]. Na verdade a população negra precisa provar, cada dia mais, que essa cidade, tão negra, vibra em cada homem e em cada mulher. [...] Não é só a cidade e a Prefeitura de Recife, não é só apoiar a Caminhada, a cidade compreende e precisa de políticas que falem sobre nossas vidas, que digam sobre nossa história. E é por essa história que nós estamos caminhando, é sobre essa história que nós vamos navegar nesse rio. ${ }^{28}$

${ }^{28}$ Fala de Rosilene na Caminhada do dia 4 de novembro de 2011. 
Ao fim do cortejo, chegamos ao Pátio da Igreja do Carmo. Havia um pequeno carro de som estacionado no pátio para a saudação à jurema sagrada. ${ }^{29}$ Sandro de Jucá iniciou a saudação à Malunguinho e depois foi seguido por vários outros juremeiros encarregados de louvar os trunqueiros, boiadeiros, caboclos, mestres e mestras da jurema. $\mathrm{O}$ pátio da igreja foi aos poucos ficando vazio e se encerrou mais uma edição da Caminhada dos Terreiros de Pernambuco.

Em um folheto distribuído em um dos seminários de preparação da Caminhada podemos ver o seguinte trecho:

Em 2010, fomos às urnas decidir que País queríamos para os próximos anos, e, já eleitos, os governantes "políticos" que ajudamos a eleger, precisam se comprometer fazendo com que as Leis Existentes no País sejam "de fato" cumpridas. Pois, nosso povo carece de reparações URGENTES, no que tange a Religião, Educação, Saúde, Segurança, Trabalho e Renda. Portanto, entendemos que, enquanto cidadãos, temos nossos direitos assegurados pela Constituição; Tudo que conquistamos foi com Luta, Suor, Lágrimas e Resistência. É importante ressaltar que Pernambuco é o segundo estado brasileiro com o maior contingente de Negros(as), como também, o de maior população de, umbanda e jurema, sendo estas duas últimas, religiões de maior culto em todo País. Não entendemos o porquê do Governo do Estado não ter um tratamento Político/Social respeitoso a esta comunidade tão expressiva de Pernambuco. Hoje, neste seguimento de luta, trazemos nossos Cânticos as mudanças que queremos para nossa população, visando o Respeito às nossas necessidades que, para nós são extremamente SAGRADAS. ${ }^{30}$

As críticas e reivindicações acima podem se estender também ao QCM. O evento/festa Kipupa Malunguinho desdobra-se em um ritual religioso que finda a Semana de Vivência e Prática da Cultura AfroPernambucana instituída pelo poder público. A Caminhada, um evento

${ }^{29}$ Eis um dos pontos do conflito entre as lideranças da Caminhada e os coordenadores do QCM. Para os últimos, a jurema deveria ter o seu lugar durante o cortejo propriamente dito, enquanto para os primeiros, as diferenças de ritualística, principalmente atribuídas aos cachimbos e a exalação das fumaças, comprometeriam a louvação aos orixás. Poderíamos destacar mais uma vez a dicotomia magia/religião para a explicação desse conflito, o que faremos em outra ocasião.

${ }^{30}$ Fonte Associação Caminhada dos Terreiros de PE (ACTP), "5 ${ }^{\text {a }}$ Caminhada dos Terreiros de Pernambuco", Folheto impresso. 2011. 
religioso e de cunho político, leva a comunidade de terreiro para as ruas reivindicando a tolerância religiosa. Através de ambos, o espaço público é construído pela esfera religiosa e a tradição se torna um ponto de encontro entre o discurso e ação. Van der Port já havia chamado a atenção para a continuidade do terreiro em outros espaços frequentados e recriados pelos candomblecistas. ${ }^{31}$

Embora percebamos que a linguagem da Caminhada seja enfaticamente política, são as questões subjetivas que a motivam, é o "beliscão do destino" subjetivo de William James que visualizamos como o estopim desse discurso. É a religião e a tradição que definem o discurso e o jogo político. Podemos novamente nos referir a Sahlins quando diz que nas diversas relações estabelecidas na experiência social as categorias são transformadas quando colocadas diante do campo de ação, diante da própria esfera da relação social.

A experiência social humana consiste da apropriação de objetos de percepção por conceitos gerais: uma ordenação de homens e dos objetos de sua existência que nunca será a única é possível, mas acredito que, nesse sentido, é arbitrária e histórica. A segunda proposição é de que o uso de conceitos convencionais em contextos empíricos sujeita os significados culturais a reavaliações práticas. As categorias tradicionais, quando levadas a agir sobre um mundo com razões próprias, um mundo que é por si mesmo potencialmente refratário são transformadas. Pois, assim como o mundo pode escapar facilmente dos esquemas interpretativos de um dado grupo humano, nada pode garantir que sujeitos inteligentes e motivados, com interesses e biografias sociais diversas, utilizarão as categorias existentes das maneiras prescritas. Chamo essa contingência dupla de o risco das categorias na ação. ${ }^{32}$

Ao pensarmos que o espaço público, tal como concebido através do processo de secularização na modernidade, é o locus onde a religião está ausente, o campo de ação empírica nos mostra o contrário. A reli-

${ }^{31}$ Mattjs van der Port, "Candomblé in Pink, Green and Black. Re-scripting the Afro-Brazilian Religious Heritage in the Public Sphere of Salvador, Bahia", Social Anthropology, v. 13, n. 1 (2005), pp.3-6.

32 Sahlins, Ilhas de História, p. 182. 
gião também é uma linguagem política. ${ }^{33} \mathrm{O}$ que impressiona é que os representantes da política "de fato" já perceberam isso e os religiosos não ficam atrás. Na realidade brasileira, o espaço público é bem mais parecido com aquele tipo de sociabilidade antropológica descrito por Gabriel Tarde, o encontro do aspecto subjetivo do sujeito/indivíduo com o público ou a opinião pública, entendida pelo autor não como essencialmente política, mas também perpassada pelo sentimento religioso e por todas as ações experimentadas no âmbito do vivido. ${ }^{34}$

O paradigma weberiano da secularização perde força em nossas experiências. Não é somente a religião como linguagem política que invade a política "de fato", a recíproca também é verdadeira. O prefeito de Recife contribuiu com sua fala no início da Caminhada. A diretora da Secretaria de Igualdade Racial legitimou na política um discurso de origem religiosa que abordou questões relacionadas à religião, à política, à etnicidade, à identidade, à raça, todas essas amparadas na ideia de tradição das matrizes afro-indígenas. A instituição escola esteve presente com as professoras no Kipupa Malunguinho, o discurso sobre a diversidade foi levantado por quem estava fora da jurema.

Ao recolocar a religião no espaço público, chegamos a uma abordagem sistêmica em que a religião refaz inversamente os caminhos propostos por Weber ${ }^{35}$ e Simmel ${ }^{36}$ sobre o processo de secularização na modernidade. A religião, enquanto expressão subjetiva nessa modernidade, retoma a expressão objetiva de coesão do social, porém de uma ordem diferente daquelas expostas pelos autores. Não mais como um processo de secularização em que a racionalidade instrumental traria o domínio das coisas sobre os homens ou a objetividade coisal da "tragé-

33 Quando utilizamos o termo linguagem nos remetemos a Jürgen Habermas, "Religion in the Public Sphere", European Journal of Philosophy, v. 14, n. 1 (2006), p. 1-25. Para o autor a religião pode ser vislumbrada como um componente linguístico que compõe a modernidade para a compreensão desta. Essa abordagem se coloca contra o paradigma de secularização de Weber, entretanto Habermas avança por meio de uma referência de procedimento embasada no direito para a busca do consenso entre o conflito de discursos normativos. Acreditamos que este último ponto não pode ser objeto de compreensão para nossa realidade brasileira.

${ }^{34}$ Gabriel Tarde, A opinião e as massas, São Paulo: Martins Fontes, 2005.

35 Max Weber, A ética protestante e o espírito do capitalismo, São Paulo: Companhia das Letras, 2004.

${ }^{36}$ Georg Simmel, "O conceito e a tragédia da cultura", in Jessé Souza e Berthold Öelze (orgs.), Simmel e a modernidade (Brasília: Editora da UnB, 2005). 
dia da cultura", mas a partir de uma criatividade própria dos sujeitos modernos. Geertz coloca a experiência para além da subjetividade do "beliscão do destino" e a amarra com termos mais firmes, como identidade e poder para a compreensão das paixões e atos que chamamos de religiosos. ${ }^{37}$

Marcos do Grac nos fala de uma ação do governo realizada em muitos terreiros:

[...] Um exemplo concreto: chegam as campanhas de vacinação e o governo simplesmente coloca a vacinação no seu terreiro, terminou a campanha ele deixa pra lá, nem obrigado ele volta pra dar, e a gente precisa de tudo. A gente precisa de que? A gente precisa de saneamento básico, a gente precisa, inclusive, de uma cozinha, a gente precisa de sanitários, a gente precisa de reforma, a gente precisa da documentação legal que é o registro de terreiro de candomblé, o que não é fácil fazer, pra que a gente possa ter... seja viável, alguns projetos sociais que o terreiro desenvolve. Porque o terreiro de candomblé, além de ser um espaço educativo, um espaço psicológico, um espaço de carinho, todo povo que precisa de um espaço religioso lá encontra. Você nunca chega numa casa pra sair de lá com fome, por incrível que pareça. Sem sair com carinho, com uma direção. Sempre buscam te dar essa consideração. Então um terreiro de candomblé é como se fosse o peito de Iemanjá, cujos filhos são peixes... você viu lá ela com o peixe, dando de mamar ao peixe, então... me arrepiei todinho... isso é coisa da gente, entendesse? ${ }^{38}$

Sua fala, acompanhada de um choro na hora que conversávamos, indica a ligação entre os aspectos subjetivos e as necessidades objetivas sentidas pelo povo de santo. Dessa forma, o pluralismo cognoscitivo nos possibilita compreender que o processo de secularização leva a religião para a arena do privado, entretanto o ethos religioso é público. ${ }^{39}$ Retornamos a Sahlins, ${ }^{40}$ quando esse diz que devemos permear o fenômeno da "organização da experiência e da ação humana por meios sim-

${ }^{37}$ Geertz, Nova luz sobre a Antropologia, p. 157

38 Marcos do Grac, em 13 de dezembro de 2011.

${ }^{39}$ Geertz, A interpretação das culturas.

40 Marshal Sahlins, "O pessimismo sentimental e a experiência etnográfica: porque a cultura não é um objeto em vias de extinção. Parte I", Mana, v.3, n.1 (1997), pp. 41-73. 
bólicos", porque a experiência humana, subjetiva, se expressa como valores e significados atribuídos socialmente. ${ }^{41}$ E o processo simmeliano de reencantamento do mundo permite que a religião venha novamente a ser pública.

Embora Simmel deixe claro que a modernidade transforma a religião em religiosidade pessoal, ${ }^{42}$ ele a reconecta com outras esferas da vida. O "beliscão do destino" possui um duplo sentido para Geertz, ${ }^{43} \mathrm{de}$ um sentimento subjetivo e profundo sobre a religião imersa na individualidade dos sujeitos, uma espécie de linguagem emotiva que reorienta as ações públicas e seus significados. Assim, podemos entender que essa linguagem emotiva, religiosa, dentro de uma linguagem política modelada pela potência das paixões religiosas, é capaz de se tornar um instrumento para a realização de propósitos. Como salientou Mãe Elza de Iemanjá, uma das responsáveis pela Caminhada dos Terreiros, sobre a autoestima do povo de santo:

Olhe, eu penso que primeiro a autoestima dos terreiros, a confiança dos terreiros no seu potencial de luta, porque eu acho que a nossa estima da reparação que nunca chegava, que toda vez é muito buscada pelo povo de terreiro, mas que infelizmente não chega, não vinha chegando. Eu acho que essa coisa da autoestima ela tá bem mais acentuada, eu acho que o respeito de um com o outro também, de nós com os outros credos, porque nós passamos a conversar com outros credos de forma mais aberta. Da Caminhada surge a ideia de fazer um fórum inter-religioso, coisa que antes Pernambuco não conversava. ${ }^{44}$

O público e o privado se entrelaçam, e mais ainda, podemos dizer, ao contrário de Weber e Simmel, que a religião na modernidade pode novamente galgar o espaço de uma esfera social que estrutura o mundo. Nesses termos, a religião é uma linguagem de compreensão sobre o mundo, um fato social total em termos maussianos. É o que percebemos com o relato de João Monteiro sobre Sandro de Jucá. Em uma das vezes que se reuniram para o grupo de estudos, no Arquivo

${ }^{41}$ Sahlins, "O pessimismo sentimental e a experiência etnográfica", p. 41.

${ }^{42}$ Simmel, "Religião".

43 Geertz, "O beliscão do destino".

44 Mãe Elza de Iemanjá, em 6 de janeiro de 2012. 
Público Estadual João Emereciano, o historiador Marcus Carvalho estava presente. Marcus fora fazer uma exposição de sua pesquisa que culminou no livro Liberdade - rotinas e rupturas do escravismo no Recife, 1822-1850. Nesse livro o autor cita a figura histórica de Malunguinho. Vamos à fala de João Monteiro, é interessante notar que esse foi o primeiro momento de encontro de Sandro com os outros coordenadores do QCM:

O depoimento de Sandro... num primeiro momento ele foi lá no Arquivo, mexeu comigo até hoje. Porque ele foi na primeira vez assistir a palestra de Marcus Carvalho. E Marcus Carvalho começou, falou da pesquisa dele e se deteve na questão de João Batista, falou de João Batista e Malunguinho e tal... então Sandro, no final da palestra a gente sempre abria o debate, e Sandro foi... "eu vim aqui dar um depoimento porque eu estou emocionado, que eu não entendia porque a minha avó, assentamento dela de Malunguinho, tinha uma imagem de São João Batista”. Era um assentamento bem antigo da avó dele. [...] Por que essa construção simbólica? Ele não entendia. E a partir da fala de Marcos Carvalho ele linkou uma coisa com a outra. Pode ser, provavelmente, pelo nome dele, o último, ter sido João Batista, a avó linkou com São João Batista e montou lá a história. ${ }^{45}$

As alianças estabelecidas para o processo de visibilidade da jurema passam por instituições (arquivo público, escola, universidades, blogs e redes sociais virtuais, prefeituras, secretarias), mídias, agentes religiosos e intelectuais. ${ }^{46}$ Como exemplo, no mês de abril de 2012, Alexandre L'Omi L'Odò foi convidado, pelo antropólogo José Jorge de Carvalho, a realizar um ritual religioso de jurema na inauguração da Sede do Instituto Nacional de Ciência e Tecnologia de Inclusão no Ensino Superior e na Pesquisa (INCTI), instituição ligada à Universidade de Brasília. Para legitimar a jurema, o QCM está num processo de se constituir em entidade jurídica, o que já aconteceu com a Caminhada

45 João Monteiro, em 14 de maio de 2011.

${ }^{46}$ Desejamos destacar que o processo de compreensão dessas alianças ocorre nos moldes metodológicos propostos por Bruno Latour em duas obras: Jamais fomos modernos, São Paulo: Editora 34, 2005; e Changer de Société. Refaire de la Sociologie, Paris: La Découverte, 2006. 
dos Terreiros, desde o ano de 2011. O QCM também vem discutindo a necessidade do povo de terreiro entrar, como alunos, nas universidades e eles próprios escreverem suas histórias. Essas ações levam, ainda, a entraves no próprio campo como conflitos entre os coordenadores da Caminhada e os coordenadores do QCM, o que culminou no nascimento da Rede Nacional do Povo da jurema que, apesar de recente, é um novo de instrumento de visibilidade que tende a ganhar cada vez mais força na disputa de poderes.

Assim, mediação entre as formas culturais (entendidas em consonância com o religioso) e políticas é um espaço privilegiado para a compreensão de como se dá a ascensão da jurema no campo religioso pernambucano, além de nos possibilitar uma compreensão sobre o espaço público como um espaço de negociações das categorias que definem o sentido da ação social. Um espaço que se estrutura na interação entre jogos de linguagem articulados em torno de elementos tanto da tradição, quanto da religião, do direito e da política, e que por este motivo, podem ser, em um sentido wittgensteiniano, publicamente acessíveis. A visibilidade da jurema ocorre não só como um movimento oriundo do campo religioso e suas disputas de poder, ela é possibilitada através do próprio espaço público que legitima, ainda que de forma incipiente e não emancipadora, o questionamento sobre o lugar de juremeiros, candomblecistas e umbandistas, agentes que buscam os valores ligados à cidadania a partir de um espaço das razões justificado principalmente através da religião. Nesse sentido, a religião afere o poder emancipador que o processo de secularização não percebe ou ignora.

Texto recebido em 23 de agosto de 2012 e aprovado em 24 de outubro de 2012 


\title{
Resumo
}

Neste artigo discutimos a ascensão da jurema no campo religioso de Recife PE. Esta religiosidade tem origem indígena e está, muitas vezes, presente nos terreiros de candomblé, xangô e umbanda. A visibilidade que a jurema tem no cenário religioso atual é vislumbrada a partir da confluência de dois rituais, o Kipupa e a Caminhada dos Terreiros de Pernambuco. Tomamos estes dois momentos como eventos que envolvem questões relacionadas à religião, à política, à tradição, à etnicidade e questões de identidade. Numa tentativa de perseguir a rede latouriana, podemos perceber disputas entre campos de poder distintos que envolvem não só as comunidades religiosas, mas que se estendem às instituições governamentais e a todo conjunto social. A mediação entre as formas culturais e políticas será um espaço privilegiado para a compreensão de como se dá a ascensão da jurema no campo religioso pernambucano.

Palavras-chave: jurema - campo religioso - política - cultura

\begin{abstract}
This article discusses the ascension of jurema in the religious sphere of Recife, Pernambuco, Brazil. This religiosity has its indigenous origin and is frequently present in terreiros of Candomblé, Xangô, and Umbanda. The visibility that jurema suffers in current religious scenario is glimpsed from the confluence of two rituals: the Kipupa and the Caminhada of Terreiros of Pernambuco. We will observe these two moments as events that involve issues related to religion, politics, tradition, ethnicity, as well as issues of identity. In an attempt to pursue the Latourian network, we can perceive disputes between distinct fields of power involving not only religious communities, but the disputes that extend to governmental institutions and to the whole social set. The mediation between cultural forms and policies will be a privileged strategy for understanding how the ascension of jurema occurs in the religious sphere of Pernambuco.
\end{abstract}

Keywords: Jurema - religious sphere - politics - culture 